\title{
COMUNICAÇÕES
}

\section{ESPLENECTOMIA E DERIVAÇÃO ESPLENO-RENAL DISTAL REALIZADAS EM SERGIPE ANTES E APÓS O PROGRAMA ESPECIAL DE CONTROLE DA ESQUISTOSSOMOSE (PECE)}

\section{Alexandre Gomes de Menezes Netto}

As avaliações referentes ao Programa Especial de Controle da Esquistossomose (PECE) procuraram medir a transmissão através dos índices de prevalência de exames de fezes positivos para área de Schistosoma ${ }^{1}$. Apresentamos informações colhidas em hospitais com o objetivo de avaliar a influência do tratamento sobre a morbidade da esquistossomose.

A partir de 1976 foram postas em prática as ações delineadas pelo Programa Especial do Controle da Esquistossomose (PECE) em Sergipe. Na fase preparatória verificou-se que a esquistossomose era incidente em seis regiōes hidrográficas numa área de $10.121 \mathrm{~km}^{2}$, de um total de $21.994 \mathrm{~km}^{2}$, com 596.522 habitantes, em 4.014 localidades e 40 municípios, dos 74 do Estado. O levantamento coproscópico foi procedido na população escolar, grupo etário de 7 a 14 anos, da área supostamente endêmica, tendo sido trabalhadas 776 escolas, com efetivação de $\mathbf{4 7 . 6 8 1}$ exames pelo método de Kato, qualitativo.

A prevalência da esquistossomose, no grupo estudado variou nos diversos municípios, entre taxas de $10,9 \%$ e $78,5 \%$ com algumas localidades chegando a $100 \%$, e com a média geral de $40,55 \%$ (Tabela 1 ).

A Biomphalaria glabrata era presente na quase totalidade dos criadouros cadastrados nos 40 municipios, assinalando-se a concomitância da Biomphalaria straminea, em alguns criadouros, dos municipios de Capela, Japaratuba e Riachuelo.

$\mathrm{Na}$ fase de ataque, como havia apenas um município, Malhada dos Bois, com 10,9\% de prevalência de esquistossomose em escolares, foi feito tratamento em massa de toda a população (Tabela 2). Nesse tipo de ação, iniciado em julho de 1977 e concluido em junho de 1978 , foram medicadas 460.937 pessoas representando $77,27 \%$ da população alvo da área delimitada. Se excluirmos a população e os medicados em Aracaju, onde os critérios foram mais flexíveis, principalmente em bairros mais centrais este percentual se eleva para $87,56 \%$.

Este trabalho faz parte da avaliação do PECE no Estado de Sergipe (CNPq/Ministério da Saúde).

Recebido para publicação em 10/11/1985.
Tabela 1 - Variação da prevalência de esquistossomose mansônica, entre escolares de 7 a 14 anos em municípios de área endêmica, no Estado de Sergipe, 1975/1976.

\begin{tabular}{cc}
\hline \multicolumn{1}{c}{ Indices } & Municipios \\
\hline 0 a $20,0 \%$ & 1 \\
20,1 a $30,0 \%$ & 10 \\
30,1 a $40,0 \%$ & 7 \\
40,1 a $50,0 \%$ & 10 \\
50,1 a $60,0 \%$ & 6 \\
60,1 a $70,0 \%$ & 2 \\
70,1 a $80,0 \%$ & 4 \\
\hline Total & 40 \\
\hline
\end{tabular}

Fonte: SEST/SUCAM, Sergipe.

O medicamento utilizado foi a oxamniquine na dose de $15 \mathrm{mg} / \mathrm{kg}$ de peso corporal para adultos, sob a fórmula de cápsulas e na dose $20 \mathrm{mg} / \mathrm{kg}$ de peso corporal para crianças até 23 quilos, em xarope ${ }^{1}$.

Simultaneamente ao tratamento medicamentoso foi feita aplicação de moluscicida nas coleções hidricas onde se constatou a existência de caramujos, a cada 60 dias, em média, merecendo especial cuidado aquelas de maior importância epidemiológica, metodologia que se tornou rotina na sistemática de trabalho na SUCAM.

Ainda dentro do elenco de medidas destinadas ao combate e a profilaxia da esquistossomose, a Fundação SESP construiu, no período 1976/1983, 26.844 privadas higiênicas; 24.399 banheiros; 19.706 tanques domiciliares para lavagem de roupa, em 22 municípios; 28 abastecimentos de água simplificados, em 28 povoados; e 3 , completos, nas cidades de Capela, Estância e São Cristóvão.

Seis meses após o tratamento medicamentoso inicial procedeu-se a primeira avaliação de resultados, através de coproscopia no mesmo grupo e remedicouse, prioritariamente, a população da faixa etária de 5 a 25 anos, onde predominava a quase totalidade dos que continuavam positivos, fato detectado nos ensaios de campo dos municípios com persistência de prevalência acima de $4 \%$. 
Comunicação. Menezes Notto AG. Esplenectomia e derivação espleno-renal distal realizadas em Sergipe antes e após o Programa Especial de Controle da Esquistossomose (PECE). Revista da Sociedade Brasileira de Medicina Tropical 20: 41-43, Jan-Mar, 1987.

Tabela 2 - Levantamentos geográfico, coproscópico e malacológico, por bacia hidrográfica e medicaçāo inicial em massa, com oxamniquine, nos municlpios do Estado de Sergipe (1976 a 1978).

\begin{tabular}{|c|c|c|c|c|c|c|c|c|c|c|c|c|}
\hline \multicolumn{4}{|c|}{ Dados Geográficos } & \multicolumn{4}{|c|}{ Coproscopia } & \multirow{3}{*}{ 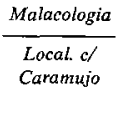 } & \multicolumn{4}{|c|}{ Medicação em massa } \\
\hline \multirow{2}{*}{$\begin{array}{c}\text { Bacia hidrografica } \\
\text { do Rio }\end{array}$} & \multirow{2}{*}{$\begin{array}{c}\text { Superficie } \\
\mathrm{Km}^{2}\end{array}$} & \multirow{2}{*}{$\begin{array}{c}\text { Localidades } \\
\text { Existentes }\end{array}$} & \multirow{2}{*}{ Populąāo } & \multirow{2}{*}{$\begin{array}{l}\text { Localidades } \\
\text { Trabalhadas }\end{array}$} & \multirow{2}{*}{$\begin{array}{c}\text { Escolas } \\
\text { Pesquisadas }\end{array}$} & \multirow{2}{*}{$\begin{array}{c}\text { Exames } \\
\text { Realizados }\end{array}$} & \multirow{2}{*}{$\begin{array}{l}\text { Positivos } \\
P / S_{\%} M\end{array}$} & & \multirow{2}{*}{$\begin{array}{l}\text { Pessoas } \\
\text { Tratadas }\end{array}$} & \multicolumn{3}{|c|}{ Pessoas nāo tratadas } \\
\hline & & & & & & & & & & Cont. Indic. & Recusas & Ausentes \\
\hline Sāo Francisco & 494 & 169 & 8.919 & 21 & 35 & 1.985 & 21,46 & 74 & 9.107 & 1.225 & 110 & 261 \\
\hline Japaratuba & 1.450 & 602 & 46.491 & 53 & 81 & 5.791 & 51,98 & 372 & 45.748 & 3.347 & 452 & 1.641 \\
\hline Sergipe & 1.370 & 682 & 276.546 & 71 & 156 & 10.811 & 51,26 & 421 & 188.616 & 38.797 & 22.510 & 31.909 \\
\hline Vasa Barnis & 1.448 & 473 & 44.667 & 29 & 55 & 4.224 & 47,57 & 232 & 43.455 & 6.260 & 505 & 1.447 \\
\hline Ріаш & 4.455 & 1.746 & 196.608 & 244 & 364 & 22.119 & 37,31 & 1.072 & 156.508 & 32.287 & 1.768 & 6.562 \\
\hline Real & 904 & 342 & 23.291 & 58 & 85 & 2.751 & 33,73 & 239 & 17.203 & 3.650 & 243 & 1.101 \\
\hline Totais & 10.121 & 4.014 & 596.522 & 476 & 776 & 47.681 & 40,55 & 2.410 & 460.937 & 85.566 & 25.588 & 42.921 \\
\hline
\end{tabular}

A segunda avaliação foi feita com a mesma metodologia, exceto em três municípios (Salgado, Indiaroba $\mathrm{e}$ Tomar do Geru) já colocados em vigilância, por apresentarem prevalência abaixo de $4 \%$. A terceira e quarta avaliaçōes passaram a ser seletivas, isto é, feitas apenas nas localidades problemáticas, de resposta insuficiente aos tratamentos e extensivas a todos os moradores dessas localidades.

Para uma avaliação através de esplenectomias e derivação espleno-renal distal logo no inicio das atividades do PECE, começamos a pesquisar nos hospitais da capital as execuções de esplenectomia, retroagindồ ao meado da década de 60 . Pretendiamos conseguir dados epidemiológicos para confrontar com uma provável realidade nova que, supostamente, surgiria com um tratamento sistematizado de todos os afetados pela doença mansônica e pelas medidas profiláticas complementares que se pretendia pôr em prática.

Dos registros constantes nos livros dos centros cirúrgicos, anotamos o nome do paciente e o do cirurgião, a cirurgia realizada, a data e o diagnóstico pré-operatório. Este último elemento, quando existente, registrado de maneira vaga e imprecisa, levou-nos a incluir no montante das esplenectomias não apenas aquelas baseadas em esplenomegalias esquistossomóticas mas também as sem diagnóstico pré-operatório. As anotações compreenderam o período de 1965 a 1985.

Após o último exame de fezes a prevalência de ovos de $S$. mansoni na área tratada variou de 4,2 a $35,3 \%$, com média geral de $8,38 \%$, ao invés dos $40,55 \%$ de antes.

No período de 1965 a 1985 cresceu o número de cirurgiōes capacitados a esplenectomizar os pacientes, maior liberalidade e precocidade nas indicações cirúrgicas, mais fácil e mais rápido acesso dos pacientes ao médico.

Quanto ao interior do Estado, pesquisas feitas revelaram que apenas nos municípios de Riachuelo $e$ Lagarto se realizaram esplenectomias, num total de 29 intervenções, sendo 17 antes e 12 depois do tratamento em massa da população.
A partir de meados de 1981 a derivação espleno-renal distal passou a ser adotada como conduta cirúrgica na hipertensão portal; até setembro de 1985 foram operados 81 casos na sua quase totalidade pela equipe do Prof. Valdinaldo Aragão e com bom padrão de acompanhamento pós-operatório.

Nos vinte anos visados pela pesquisa 0 Estado de Sergipe aumentou sua população em $58 \%$, as cirurgias gerais, na Capital, cresceram cerca de $600 \%$ e em termos relativos passaram de 3,22 por 1.000 habitantes para 13,92 (Tabela 3).

As esplenectomias, agora acrescidas pelas derivações, representavam no passado até $2,5 \%$ de todas as cirurgias realizadas, hoje situa-se nos $0,28 \%$; em números relativos caiu de até 0,137 por 1.000 habitantes para os atuais 0,039 (Tabela 3 e Fig. 1).

Observa-se que a queda nas cirurgias corretivas da hipertensão portal efetivamente se acentuou após o tratamento em massa da população, ao lado de outras medidas profiláticas citadas no texto, o que autoriza a afirmação de que a gênese dos casos graves de esquistossomose em Sergipe reduziu-se dramaticamente e confirma o sensivel declínio da prevalência da doença bem como da intensidade das infestaçôes.

\section{AGRADECIMENTOS}

Agradecemos aos Drs. José Eduardo Sobral, Edgar Alves da Silva Filho e Nadya Lins Porto pelas pesquisas de dados nos hospitais. Ao Dr. Cleovansóstenestes Pereira de Aguiar pela revisão. À Maria Angélica Araújo Matos pela datilografia. Ao Prof. Valdinaldo Aragão pelo fornecimento de dados estatísticos, FSESP, SUCAM, INEP-SE e ao Prof. Aluizio Prata pelo estimulo e revisão.

\section{REFERÊNCIA BIBLIOGRÁFICA}

1. Machado PA. Painel do Programa Especial de Controle da Esquistossomose. VI. Conferência Nacional de Saúde, Brasilia, 1977. 
Comunicação. Menezes Netto AG. Esplenectomia e derivação espleno-renal distal realizadas em Sergipe antes e após o Programa Especial de Controle da Esquistossomose (PECE). Revista da Sociedade Brasileira de Medicina Tropical 20: 41-43, Jan-Mar, 1987.

Tabela 3 - População, Cirurgias Gerais, Esplenectomias + Derivaçōes Espleno-Renais Distais realizadas e suas relaçōes no período de 1965/1985(*).

\begin{tabular}{|c|c|c|c|c|c|c|}
\hline Anos & $\begin{array}{l}\text { População } \\
\text { estadual }\left(^{* *}\right)\end{array}$ & $\begin{array}{l}\text { Cirurgias } \\
\text { gerais } \\
\text { realizadas }\end{array}$ & $\begin{array}{c}\text { Esplenectomias } \\
+ \text { derivaçóes } \\
\text { realizadas }\end{array}$ & $\begin{array}{c}\text { Cirurgias gerais } \\
\text { p/1.000 habitantes }\end{array}$ & $\begin{array}{c}\text { Esplenectomias } \\
+ \text { derivaçōes } \\
p / 1.000 \text { habitantes }\end{array}$ & $\begin{array}{l}\text { Relaçäo percentual } \\
\text { entre cirurgia geral } \\
\text { e esplenectomias } \\
+ \text { derivacōes }\end{array}$ \\
\hline 1965 & 812.000 & 2.618 & 23 & 3,22 & 0,028 & 0,87 \\
\hline 1966 & 825.000 & 3.220 & 46 & 3,90 & 0,055 & 1,42 \\
\hline 1967 & 838.000 & 3.196 & 68 & 3,81 & 0,081 & 2,12 \\
\hline 1968 & 851.000 & 3.840 & 65 & 4,51 & 0,076 & 1,69 \\
\hline 1969 & 864.000 & 3.965 & 82 & 4,58 & 0,094 & 2,06 \\
\hline 1970 & 900.744 & 4.949 & 124 & 5,49 & 0,137 & 2,50 \\
\hline 1971 & 917.140 & 5.502 & 87 & 5,67 & 0,094 & 1,58 \\
\hline 1972 & 933.830 & 5.294 & 93 & 5.66 & 0,099 & 1,75 \\
\hline 1973 & 950.830 & 6.626 & 123 & 6,96 & 0,129 & 1,85 \\
\hline 1974 & 968.130 & 7.071 & 116 & 7,30 & 0,119 & 1,64 \\
\hline 1975 & 985.750 & 7.527 & 89 & 7,63 & 0,090 & 1,18 \\
\hline 1976 & 1.003 .690 & 7.489 & 89 & 7,46 & 0,088 & 1,18 \\
\hline 1977 & 1.021 .960 & 7.362 & 113 & 7,20 & 0,110 & 1,53 \\
\hline 1978 & 1.040 .560 & 9.814 & 129 & 9,43 & 0,123 & 1,31 \\
\hline 1979 & 1.059 .500 & 12.035 & 97 & 11,35 & 0,091 & 0,80 \\
\hline 1980 & 1.140 .121 & 15.127 & 90 & 13,26 & 0,078 & 0,59 \\
\hline 1981 & 1.167 .370 & 21.944 & 71 & 18,79 & 0,060 & 0,32 \\
\hline 1982 & 1.195 .270 & 14.453 & 52 & 12,09 & 0,043 & 0,35 \\
\hline 1983 & 1.223 .840 & 17.782 & 53 & 14,53 & 0,043 & 0,29 \\
\hline 1984 & 1.254 .970 & 17.618 & 58 & 14,04 & 0,046 & 0,32 \\
\hline $1985\left(^{*}\right)$ & 1.284 .960 & 17.884 & 51 & 13,92 & 0,039 & 0,28 \\
\hline
\end{tabular}

(") até setembro

(*) Fonte: 1970 e 1980 - Recenseamento Geral; demais anos, estimativa do INEP-SE.

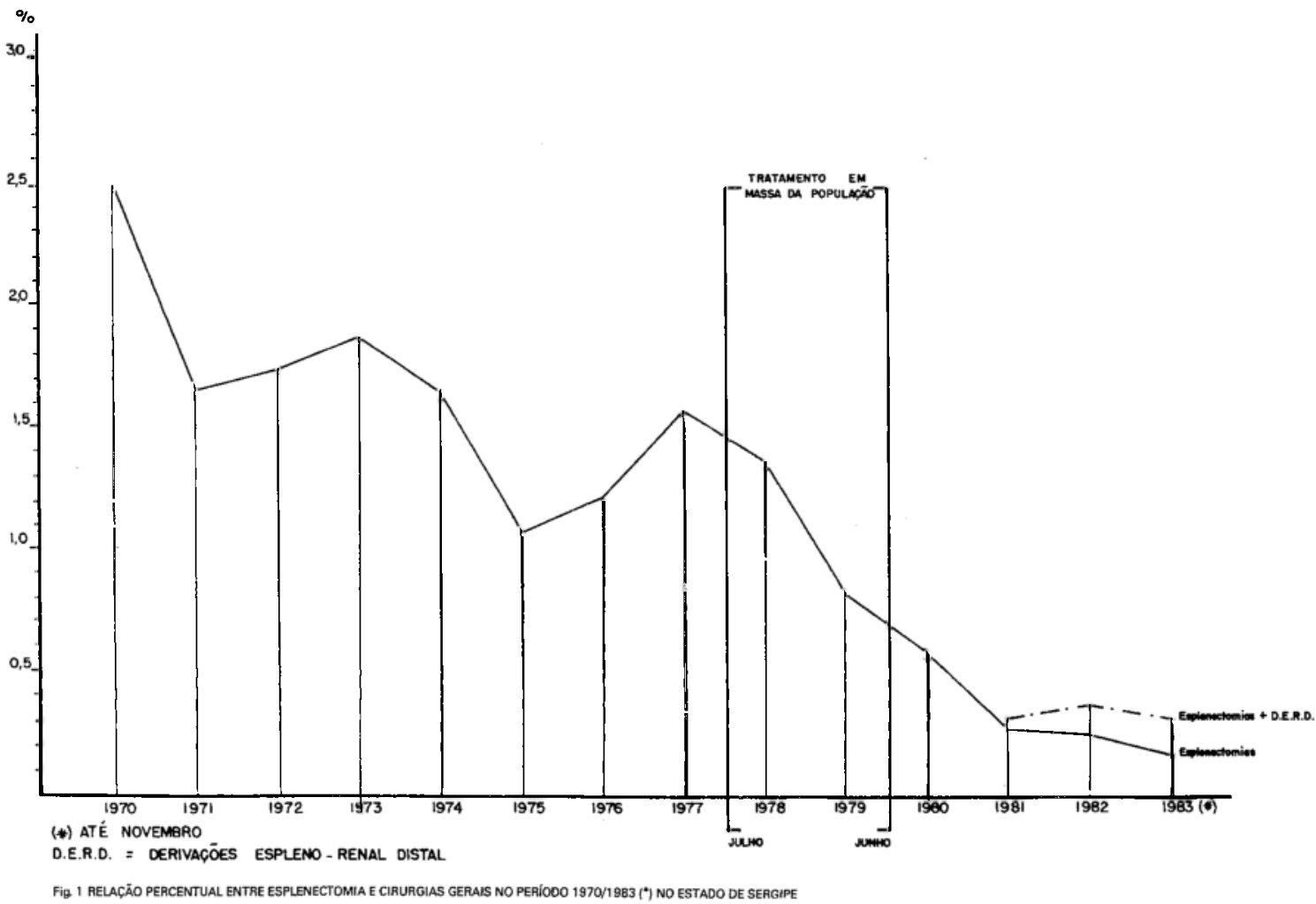

